\title{
Crescimento, produção de fitomassa e teor de óleo essencial de folhas de capim citronela (Cymbopogon nardus (L.) Rendle) em cultivo consorciado com algodoeiro colorido no semiárido mineiro
}

\author{
ROCHA, H.C.R. ${ }^{1 *}$; ALVARENGA, C.D. ${ }^{1}$; GIUSTOLIN, T.A. ${ }^{1}$; BRANT, R.S. ${ }^{2}$; SOUZA, M.D.C. ${ }^{1}$; SARMENTO, H.G.S. ${ }^{1}$; \\ BARBOSA, M.G. ${ }^{1}$ \\ 1 Universidade Estadual de Montes Claros. Avenida Reinaldo Viana, 2630, Bico da Pedra, CEP: 39440-000, Janaúba-

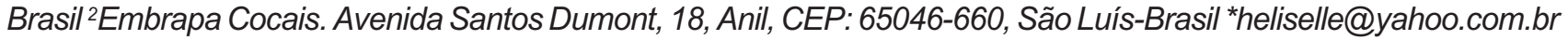

\begin{abstract}
RESUMO: Avaliou-se o crescimento, a produção e o teor do óleo essencial de dois cortes de capim citronela em cultivo consorciado com algodoeiro colorido no semiárido. Para isso foram utilizados dois sistemas de consórcios (tratamentos): algodão colorido consorciado com capim citronela $3 \times 1$ e algodão colorido consorciado com capim citronela 1x1. A variedade de algodão colorido utilizada foi a BRS Rubi e as mudas de capim citronela foram produzidas no Horto de Plantas Medicinais da Unimontes. O delineamento experimental utilizado foi em blocos casualizados com dois tratamentos e 16 repetições. O experimento foi mantido em regime de sequeiro e foi avaliado a altura das plantas de capim citronela. Foram realizadas duas colheitas das folhas de capim citronela, sendo a primeira no momento da colheita da fibra do algodão e a segunda na rebrota do capim, seis meses após. Todas as plantas da parcela foram colhidas e as folhas frescas foram pesadas, no campo, com o auxílio de balança digital. Amostras das folhas colhidas foram retiradas e levadas para secagem em estufa com circulação forçada de ar a $35^{\circ} \mathrm{C}$ até atingirem massa constante. Foi verificada a massa seca e posteriormente realizada a extração do óleo essencial pelo método de hidrodestilação em aparelho modificado de Clevenger. Os dados foram submetidos à análise de variância e as médias comparadas pelo teste Skott-Knott $(p<0,05)$. A altura das plantas não diferiu entre os tratamentos nas colheitas. Para a produção de massa fresca e seca houve diferença entre os tratamentos apenas na segunda colheita. Neste caso, as plantas cultivadas em consórcio $1 \times 1$ produziram mais do que as do consórcio $3 \times 1$. 0 teor de óleo essencial de capim citronela não variou entre os dois sistemas de consórcio, tanto no primeiro como no segundo corte.
\end{abstract}

Palavras-chave: policultivo, rebrota

ABSTRACT: Growth, phytomass yield and essential oil content of leaves of citronella grass [Cymbopogon nardus (L.) Rendle] intercropping with colored cotton. The research was performed to evaluate the growth, production and essential oil content of the two harvests of citronella grass in intercropped with colored cotton in semiarid.For this, was used two system consortium (treatments): colored cotton intercropped with citronella grass $3 \mathrm{X} 1$ and colored cotton intercropped with citronella grass $1 \mathrm{X} 1$. The variety of colored cotton used was BRS Rubi and the citronella grass seedlings were produced in the Medicinal Plants Garden of Unimontes. The experimental design used was randomized blocks with two treatments and 16 repetitions. The experiment was maintained under rainfed conditions. Was evaluated plant height of citronella grass. Citronella grass leaves were harvested twice: the first was made at harvest of cotton fiber and the second in the grass regrowth, six months later. All plants in the plot were harvested and the fresh leaves were weighed, in the field, with the aid of a digital balance. Samples from leaves harvested were collected and taken for drying in an oven with forced air at $35^{\circ} \mathrm{C}$ until reaching constant weight. Dry mass was verified and the performed the extraction of essential oil by hydrodestilation in Clevenger modified apparatus. Data were subjected to analysis of variance and means compared by Skott-Knott test $(p<0.05)$. The plants height did not differ between treatments in harvests. For the production of fresh and dry mass was significant difference between treatments only in the second harvest. In this case the plants cultivated in the consortium 1x1 produced more than in the consortium $3 \times 1$. The essential oil content of citronella grass did not vary between the two systems consortium, in the first and the second harvest.

Key words: polyculture, regrowth

Recebido para publicação: setembro de 2011

Aceito para publicação: março de 2012

Rev. Bras. PI. Med., Botucatu, v.14, n.esp., p.183-187, 2012. 


\section{INTRODUÇÃO}

O policultivo envolve o crescimento simultâneo de duas ou mais culturas na mesma área (Altieri, 1989) é um recurso importante no manejo dos sistemas agroecológicos, potencializando a produção de alimentos e suprindo melhor as demandas nos aspectos sociais, econômico e ambiental (Silva et al., 2009). Sua adoção, mais do que representar apenas uma tática do MIP das culturas, pode ser o grande diferencial para se atingir a sustentabilidade (Bastos et al., 2006).

Dentre as vantagens do policultivo a mais citada é a redução do ataque de pragas, pois insetos herbívoros normalmente alcançam maiores densidades populacionais em monocultivos do que em estandes com diversidade de culturas (Coll \& Bottrel, 1994). A maior dificuldade encontrada pelos insetos-praga em localizar os hospedeiros nos policultivos se deve ao fato de que o encontro da planta hospedeira pelos insetos envolve percepção olfativa de substâncias voláteis emitidas pelas plantas. Sendo assim, a emissão de voláteis por plantas não hospedeiras e constituintes do policultivo pode dificultar a localização da planta- hospedeira pelo inseto-praga (Altieri, 1989).

A redução do ataque de pragas é uma característica importante para os produtores de algodão do Norte de Minas, tendo em vista que a cultura sofre com o ataque de insetos, que são favorecidos pelas condições climáticas, além do baixo nível tecnológico em que a lavoura é cultivada, em função, principalmente, da falta de recursos dos pequenos produtores da região (Gabriel et al., 1997). O cultivo do algodoeiro em consórcio com outras culturas pode contribuir com o aumento da receita da propriedade familiar (Silva et al., 2009). O policultivo possibilita a melhor utilização da área por meio do cultivo concomitante de culturas geradoras de renda (Bastos et al., 2006).

Dessa forma, plantas aromáticas com propriedades repelentes poderia ser uma alternativa para os agricultores familiares utilizarem em cultivos consorciados visando manter a população de insetospraga em baixos níveis. O capim citronela (Cymbopogon nardus (L.) Rendle), conhecido pelas propriedades repelentes, poderia ser uma opção interessante, pois é uma planta que pode ser cultivada na maioria dos solos e possui bom desenvolvimento em climas tropicais e subtropicais (Castro \& Ramos, 2003). Desta forma torna-se possível cultivá-lo em diferentes regiões geográficas do Brasil, visto que o capim citronela é muito resistente ao ataque de pragas e às variações climáticas (Vargas et al., 2006), características importantes para o cultivo no Norte de Minas.

Além da bioatividade sobre os insetos, o capim citronela poderia também ser utilizado ou comercializado para a obtenção de óleo essencial, já que esta planta medicinal e aromática tem crescido em importância no Brasil devido à grande procura pelo óleo essencial, tanto no mercado interno, quanto para exportação (Rocha et al., 2000). Portanto, o uso promoveria a utilização da terra mais eficientemente garantindo aos agricultores familiares uma produção sustentável e mais rentável.

Sendo assim, objetivou-se avaliar o crescimento, a produção de massa fresca e seca e o teor de óleo essencial de capim citronela cultivado em consórcio com algodoeiro de fibra colorida no semiárido mineiro.

\section{MATERIAL E MÉTODO}

O experimento foi instalado em uma área experimental no município de Janaúba, região semiárida do Norte de Minas Gerais. A classificação do clima da região, segundo Köppen é Aw, caracterizado por chuvas concentradas no verão e secas nos meses do inverno. Possui pluviosidade média anual de $871 \mathrm{~mm}$, concentrados de novembro a março. A temperatura média anual é de $24^{\circ} \mathrm{C}$ e as médias de verão e inverno são $32^{\circ} \mathrm{C}$ e $19,5^{\circ} \mathrm{C}$, respectivamente. A insolação é de 2.763 horas anuais com umidade relativa média de $70,6 \%$, sendo que no período seco pode chegar a $20 \%$ (Rodrigues et al., 2002).

Foram utilizados dois sistemas de consorciamento com algodoeiro, o do algodãocolorido consorciado com capim-citronela $3 \times 1$ (semeio de três linhas de algodão-colorido seguidas pelo transplantio em consórcio de uma linha de capimcitronela) e o do algodão-colorido consorciado com capim-citronela 1x1 (semeio de uma linha de algodãocolorido seguida pelo transplantio em consórcio de uma linha de capim-citronela). O delineamento utilizado foi o em blocos casualizados com dois tratamentos e 16 repetições. Cada parcela experimental, com uma área de $81 \mathrm{~m}^{2}$, foi constituída de nove linhas de nove metros de comprimento limitada por uma bordadura de três linhas de algodão colorido.

As mudas de capim-citronela foram produzidas a partir da remoção manual dos perfilhos provenientes de touceiras de plantas mães mantidas no Horto de Plantas Medicinais. Os perfilhos, destacados manualmente, foram preparados com o corte do excesso radicular e da parte vegetativa acima de $20 \mathrm{~cm}$ da intersecção radicular. Posteriormente, os perfilhos mais desenvolvidos foram plantados em sacos de polietileno de $20 \mathrm{~cm}$ de diâmetro que continham no interior uma mistura de solo mais esterco bovino curtido. Após o plantio, as mudas foram mantidas no viveiro por um período de quatro meses, sob sistema de irrigação, até serem transplantadas

Rev. Bras. PI. Med., Botucatu, v.14, n.esp., p.183-187, 2012. 
no campo.

Para o semeio do algodão-colorido foram utilizadas sementes da variedade BRS Rubi obtidas do banco de germoplasma da Embrapa Algodão. $O$ espaçamento utilizado foi de 1,0 m x 0,14 m (sete plantas por metro linear). Simultaneamente ao semeio foram transplantadas as mudas de capimcitronela em covas $(0,30 \mathrm{~m} \times 0,30 \mathrm{~m} \times 0,30 \mathrm{~m})$ espaçadas de $1,0 \mathrm{~m} \times 0,5 \mathrm{~m}$ (duas plantas por metro linear). $O$ experimento foi conduzido em regime de sequeiro e a adubação feita somente com esterco bovino curtido. As culturas foram mantidas "no limpo" por meio da capina manual e nenhum defensivo agrícola foi aplicado durante o cultivo.

O capim citronela foi colhido em dois momentos. A primeira colheita foi realizada no início de junho de 2010, juntamente com a colheita das fibras do algodão colorido. A segunda colheita ocorreu após a rebrota do capim citronela em janeiro de 2011. A colheita consistiu do corte das folhas do capim citronela a uma altura aproximada de $20 \mathrm{~cm}$ acima do nível do solo. Todas as plantas da parcela foram colhidas e as folhas frescas foram pesadas em balança digital ainda no campo. Uma amostra de aproximadamente $500 \mathrm{~g}$ de folhas de cada uma das parcelas foram retiradas e levadas para secagem em estufa de circulação forçada de ar a $35^{\circ} \mathrm{C}$ até atingirem massa constante visando a quantificação da massa seca e a extração do óleo essencial. Antes das colheitas foi medida a altura de três plantas de capim citronela em cada linha de plantio de todas as parcelas com o auxílio de trena.

Ao atingirem massa constante, as folhas secas de capim citronela de cada uma das parcelas foram submetidas ao processo de extração do óleo essencial através do método de hidrodestilação em aparelho modificado de Clevenger. As folhas secas de capim citronela foram colocadas em balão volumétrico de $1 \mathrm{~L}$ onde foi acrescentado o volume de $750 \mathrm{~mL}$ de água destilada. Esta mistura foi aquecida e mantida na temperatura mínima necessária até a ebulição. $O$ tempo de extração foi de 90 minutos, contados a partir do momento da ebulição. Finalizado este tempo, o hidrolato foi retirado da coluna de extração do Clevenger e esta foi lavada com diclorometano para recolher possíveis resíduos da amostra.

O hidrolato obtido de cada uma das amostras foi submetido à partição líquido-líquido em funil de separação, com três porções de $25 \mathrm{~mL}$ de diclorometano. Cada porção descansou por 20 minutos, totalizando 60 minutos por repetição. A fração orgânica (óleo + solvente) proveniente do funil de separação foi coletada em um erlenmeyer de $100 \mathrm{~mL}$ e, em seguida, tratada com sulfato de magnésio anidro (MgSO4) em excesso para a retirada da água remanescente. A remoção do sal foi realizada através de filtração simples e o solvente evaporado à temperatura ambiente até ser alcançado peso constante.

A quantificação do óleo essencial foi realizada por meio da pesagem do óleo em balança analítica. O teor de óleo essencial nas folhas foi determinado por meio da relação da quantidade de óleo obtido (g) com a quantidade de folha seca (g) utilizada na extração e o resultado foi expresso em porcentagem (\%).

Os dados foram submetidos à análise de variância e as médias foram comparadas pelo teste de Skott-Knott $(p<0,05)$. As análises foram realizadas no programa estatístico Sisvar 4.0 (Ferreira, 2000).

\section{RESULTADO E DISCUSSÃO}

Para a primeira colheita do capim citronela não se observou diferença para a característica altura das plantas, e nem para a massa fresca e seca (Tabela 1). Em ambos os sistemas de consórcio, 1x1 e 3x1, as plantas se desenvolveram de modo semelhante.

Após a rebrota foi constatado crescimento similar do capim citronela nos dois arranjos de consórcio, não havendo diferença para a altura média das plantas (Tabela 2). No entanto, observou-se que no cultivo consorciado $1 \times 1$ (semeio de uma linha de algodão colorido seguida de uma linha de capim citronela) a massa fresca e massa seca por planta foram superiores em relação às produções obtidas no cultivo $3 \times 1$ (semeio de três linhas de algodão colorido seguidas de uma linha de capim citronela) (Tabela 2). Isso pode ser atribuído ao fato de nesse

TABELA 1. Altura média ( $\mathrm{cm})$, massa fresca por planta $(\mathrm{g})$ e massa seca por planta $(\mathrm{g})$ de capim citronela

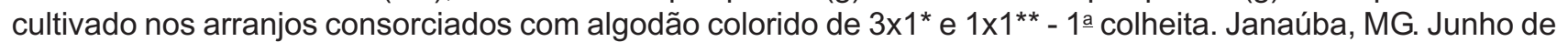
2010.

\begin{tabular}{lccc}
\hline Tratamentos & Altura $(\mathbf{c m})$ & MFresca $(\mathbf{g})$ & MSeca $(\mathbf{g})$ \\
\hline Capim citronela consorciado $3 \times 1$ & $68,81 \mathrm{a}$ & $1.150,00 \mathrm{a}$ & $473,75 \mathrm{a}$ \\
Capim citronela consorciado $1 \times 1$ & $71,04 \mathrm{a}$ & $1.218,75 \mathrm{a}$ & $491,25 \mathrm{a}$ \\
\hline
\end{tabular}

Médias seguidas pela mesma letra não diferem entre si pelo teste de Skott-Knott $(p<0,05)$. *3x1: Sistema de consórcio com três linhas de plantio de algodoeiro de fibra colorida e uma linha de plantio de capim citronela. ${ }^{* *} 1 \times 1$ : Sistema de consórcio com uma linha de plantio de algodoeiro de fibra colorida e uma linha de plantio de capim citronela.

Rev. Bras. PI. Med., Botucatu, v.14, n.esp., p.183-187, 2012. 
sistema haver maior cobertura do solo, uma vez que o sistema possuía mais plantas por área. Dessa forma, haveria a manutenção da umidade do solo por um maior tempo, tendo em vista que a rebrota coincidiu com a época de maiores precipitações na região.

Castro et al. (2007) avaliando o desenvolvimento e produção de massa fresca e seca de capim citronela em Tocantins encontraram que, aos 168 dias após transplante, as plantas atingiram $3.305,63 \mathrm{~g}$ de massa fresca e 1.279,05 g de massa seca. Ao se comparar os resultados obtidos neste trabalho com aqueles obtidos pelos autores pode-se notar que a produção de massa fresca e seca foi menor. Isto pode ser justificado pelo número de perfilhos utilizados no preparo das mudas. Neste trabalho foi utilizado apenas um perfilho, enquanto que no estudo realizado por Castro et al. (2007) foram utilizados três perfilhos.

Com relação aos resultados obtidos para o teor de óleo essencial nas plantas de capim citronela, verificou-se que tanto para a primeira quanto para a segunda colheita, não houve diferença entre os dois sistemas consorciados com algodoeiro colorido (3x1 e 1x1) (Tabelas 3 e 4).

Em outros estudos sobre densidades de plantio envolvendo diferentes espécies do gênero Cymbopogon, Yadava (2001) e Blank et al. (2007b) também não observaram diferenças significativas quanto ao teor de óleo essencial.

Os teores médios de óleo essencial de capim citronela obtidos neste trabalho foram baixos quando comparados a alguns dados da literatura. Castro et al. (2007) observaram um teor de 1,15\% de óleo essencial em plantas de capim citronela cultivadas em sistema solteiro em Tocantins. $O$ baixo teor de óleo essencial nas plantas de capim citronela pode ser justificado pelo fato de os óleos essenciais serem voláteis em temperaturas maiores que $35^{\circ} \mathrm{C}$. Nos sistemas consorciados estudados havia pouco sombreamento na área pelo fato de o algodoeiro

TABELA 2. Altura média (cm), massa fresca por planta $(\mathrm{g})$ e massa seca por planta $(\mathrm{g})$ de capim citronela cultivado nos arranjos consorciados com algodão colorido de 3x1 e 1x1 - 2a colheita. Janaúba, MG. Janeiro de 2011.

\begin{tabular}{lccc}
\hline Tratamentos & Altura $(\mathbf{c m})$ & MFresca $(\mathbf{g})$ & MSeca $(\mathbf{g})$ \\
\hline Capim citronela consorciado $3 \times 1$ & 45,29 a & 825,39 b & 303,50 b \\
Capim citronela consorciado $1 \times 1$ & 46,89 a & $1.050,80$ a & 415,15 a
\end{tabular}

Médias seguidas pela mesma letra na coluna não diferem entre si pelo teste de Skott-Knott $(p<0,05)$. *3x1: Sistema de consórcio com três linhas de plantio de algodoeiro de fibra colorida e uma linha de plantio de capim citronela. ${ }^{* *} 1 \times 1$ : Sistema de consórcio com uma linha de plantio de algodoeiro de fibra colorida e uma linha de plantio de capim citronela.

TABELA 3. Resumo da análise de variância para teor de óleo essencial de capim citronela cultivado em consórcio com algodão colorido - 1a Colheita. Janaúba, MG. Junho de 2010.

\begin{tabular}{ccc}
\hline Fontes de variação & Graus de liberdade & Quadrados Médios \\
\hline Consórcios & 1 & $0,028800 \mathrm{~ns}$ \\
Bloco & 15 & $0,000810 \mathrm{~ns}$ \\
\hline
\end{tabular}

C.V. (\%): 17,47

Média geral: 0,2038

ns : não significativo pelo teste $\mathrm{F}$ a $5 \%$ de probabilidade.

TABELA 4. Resumo da análise de variância para teor de óleo essencial de capim citronela cultivado em consórcio com algodão colorido - 2a Colheita. Janaúba, MG. Janeiro de 2011.

\begin{tabular}{ccc}
\hline Fontes de variação & Graus de liberdade & Quadrados Médios \\
\hline Consórcios & 1 & $0,065703 \mathrm{~ns}$ \\
Bloco & 15 & $0,000828 \mathrm{~ns}$ \\
\hline
\end{tabular}

C.V. (\%): 12,26

Média geral: 0,3141

ns : não significativo pelo teste $\mathrm{F}$ a $5 \%$ de probabilidade. 
possuir pequena parte aérea. Dessa forma, o microclima com maior incidência de luz e maior temperatura, pode ter favorecido a volatilização do óleo essencial.

A biossíntese de metabólitos secundários, apesar de controlada geneticamente, é fortemente afetada pelos fatores ambientais (Blank et al., 2007a). De acordo com Simões et al. (1999), os óleos essenciais são misturas complexas e apresentam as características de volatilidade, sendo pouco estáveis principalmente em presença de luz, calor e outros.

A partir dos resultados da análise de massa fresca, massa seca e do teor de óleo essencial obtidos, pode-se projetar para o primeiro corte uma produtividade de $11.842,86 \mathrm{~kg} \mathrm{ha}^{-1}$ de massa fresca, $4.777,68 \mathrm{~kg} \mathrm{ha}^{-1}$ de massa seca e de $8,03 \mathrm{~kg} \mathrm{ha}^{-1} \mathrm{de}$ óleo essencial para o sistema de consórcio $1 \times 1$. Já para o sistema consorciado $3 \times 1$, estima-se uma produtividade de $5.650,00 \mathrm{Kg} \mathrm{ha}^{-1}$ de massa fresca, $2.320,00 \mathrm{Kg} \mathrm{ha}^{-1}$ de massa seca e de $5,43 \mathrm{Kg} \mathrm{ha}^{-1} \mathrm{de}$ óleo essencial de citronela.

Para o segundo corte, a produtividade média de massa fresca, massa seca e de óleo essencial pode ser estimada, no sistema de consórcio de 1x1, em $9.600 \mathrm{Kg} \mathrm{ha}^{-1}, 3.662,55 \mathrm{Kg} \mathrm{ha}^{-1}$ e $6,56 \mathrm{Kg} \mathrm{ha}^{-1}$, respectivamente. Para o sistema de consórcio $3 \times 1$ a projeção para a produtividade média de massa fresca é de $3.317,86 \mathrm{Kg} \mathrm{ha}^{-1}$, de massa seca de 1.257,46 e de óleo essencial de $3,96 \mathrm{Kg} \mathrm{ha}^{-1}$.

De acordo com os dados obtidos, pode-se concluir que ambos os sistemas de consórcio propiciaram um crescimento semelhante, tanto no primeiro quanto no segundo corte. Após a rebrota há uma maior produção por planta de massa fresca e seca de folhas de capim citronela no sistema consorciado 1x1, não havendo diferença entre os dois sistemas de consórcio no primeiro corte. O teor médio de óleo essencial é de $0,2038 \%$ e de $0,3141 \%$ para o primeiro e segundo corte, respectivamente.

\section{AGRADECIMENTO}

Os autores agradecem à Finep pelo apoio financeiro e à Fapemig e Capes pela concessão de bolsas aos autores.

\section{REFERÊNCIA}

ALTIERI, M.A. Agroecologia: as bases científicas da agricultura alternativa. Rio de Janeiro: Projeto Tecnologias Alternativas-Fase, 1989. 237p.

BASTOS, C.S. et al. Cultivo agroecológico do algodoeiro e a convivência com insetos fitófagos: possibilidade ou realidade. Campina Grande: Embrapa Algodão, 2006. 68p. (Embrapa Algodão. Documentos, 163).

BLANK, A.F. et al. Densidades de plantio e doses de biofertilizante na produção de capim-limão. Horticultura Brasileira, v.25, n.3, p.343-9, 2007a.

BLANK, A.F. et al. Infuence of season, harvest time and drying on Java citronella (Cymbopogon winterianus Jowitt) volatile oil. Revista Brasileira de Farmacognosia, v.17, p.557-64, 2007b.

CASTRO, H.G. et al. Crescimento, teor e composição do óleo essencial de Cymbopogon nardus (L.). Revista Brasileira de Plantas Medicinais, v.9, n.4, p.55-61, 2007. CASTRO, L.O.; RAMOS, R.L.D. Principais gramíneas produtoras de óleos essenciais. Boletim Técnico da Fundação Estadual de Pesquisa Agropecuária, n.11, 28 p., 2003. Disponível em <http://www.esalq.usp.br/ siesalq/pm/gramineas.pdf>. Acesso em: 11 jan. 2011. COLL, M.; BOTTRELL, D.G. Effects of nonhost plants on an insect herbivore in diverse habitats. Ecology, v.75, p.723-31, 1994.

FERREIRA, D.F. Análises estatísticas por meio do Sisvar para Windows versão 4.0. In: REUNIÃO ANUAL DA REGIÃO BRASILEIRA DA SOCIEDADE INTERNACIONAL DE BIOMETRIA, 45., 2000, São Carlos. Programas e resumos... São Carlos: UFSCar, 2000. p.255-8.

GABRIEL, D.; SCARPELLINI, J.R.; BOLONHEZI, D. Influência da época de plantio na produtividade do algodoeiro em áreas infestadas pelo bicudo Anthonomus grandis (Boh), Safra 1996/97. In: CONGRESSO BRASILEIRO DO ALGODÃO, 1., 1997, Fortaleza. Anais... Campina Grande: EMBRAPA-CNPA, 1997. p.15-17.

ROCHA, S.F.R.; MING, L.C.; MARQUES, M.O.M. Influência de cinco temperaturas de secagem no rendimento e composição do óleo essencial de citronela Cymbopogon winterianus Jowitt. Revista Brasileira de Plantas Medicinais, v.3, n.1, p.73-8, 2000.

RODRIGUES, M.G.V.; SOUTO, R.F.; MENEGUCCI, J.L.P. Efeito da poda da última penca do cacho da bananeira prata anã $(A A B)$ irrigada na produção de frutos no norte de Minas Gerais. Revista Brasileira de Fruticultura, v.24, n.1, p.108-10, 2002.

SILVA, M.N.B.; ALVES, G.S.; WANDERLEY JUNIOR, J.S.A. Manejo cultural do algodoeiro agroecológico no semiárido brasileiro. Campina Grande: Embrapa Algodão, 2009. 10p. (Embrapa Algodão. Circular Técnica, 126).

SIMÕES, C.M.O. et al. Farmacognosia: da planta ao medicamento. Porto Alegre/Florianópolis: UFRGS/UFSC. 1999. 821p.

VARGAS, R.M.F.; CASSEL, E.; SOUZA, C.C. Experiments and modeling of the Cymbopogon winterianus essential oil extraction by steam Distillation. Journal of the Mexical Chemical Society, v.50, p.126-9, 2006.

YADAVA, A.K. Cultivation of lemon grass (Cymbopogon flexuosus, 'CKP-25') under Poplar based agroforestry system. Indian Forester, v.127, p.213-23, 2001. 